\title{
ESPAÇO ABERTO
}

\section{Experiência moderna e as dificuldades para a educação formal}

CESAR AUGUSTO ALVES DA SILVA Universidade de São Paulo, São Paulo, SP, Brasil

A horrivel mixórdia de estilos e concep̧ões do mundo do século passado mostrou-nos com tanta clareza aonde esses valores culturais podem nos conduzir quando a experiência nos é subtraída, bipócrita

ou sorrateiramente, que é hoje em dia uma prova de honradez confessar nossa pobreza. Sim, é preferivel confessar que essa pobreza de experiência não é mais privada, mas de toda a humanidade.

Surge assim uma nova barbárie. Walter Benjamin, 1994b, p. 115

O homem moderno não cultiva nada que não possa ser abreviado. Paul Valèry apud Benjamin, 1994a, p. 206

\section{PRODUÇÃO, TROCA E ALIENAÇÃO DA EXPERIÊNCIA FORMATIVA DOS SERES HUMANOS NA MODERNIDADE CAPITALISTA}

A apreensão do mundo material efetuada pela racionalidade técnica instrumental da indústria capitalista, e com ela a dominação do ser humano em todas as esferas de sua vida, fez com que o âmbito material se tornasse o principal ponto de referência para a vida no mundo moderno, burguês e capitalista. É todo um ambiente que se cria movido pelos preceitos da indústria e que aos poucos educa 
informalmente os seres humanos, isto é, os identifica - entre si mesmos, mas, acima de tudo, por uma ordem econômica externa a qualquer objetivo humano. Tanto dentro quanto fora do espaço da produção, que é regida pelos objetivos de ganho e lucro, imperam os mesmos estímulos. "À vivência do choque sentida pelo transeunte na multidão, corresponde a 'vivência' do operário com a máquina” (Benjamin, 1989, p. 126).

Mesmo que a cultura empreendida pela razão burguesa coloque o contrário, trata-se de uma questão eminentemente material. O indivíduo moderno foi invadido em sua vida, tanto externa quanto internamente - ou seja, tanto pública quanto privada - pela lógica das relações produtivas capitalistas. A experiência estética, isto é, a constituição da sensorialidade dos indivíduos modernos, foi subsumida às relações materiais de produção que envolvem o âmbito social e fazem com que os seres humanos sucumbam a elas.

O homem e a mulher modernos passam a ser regidos, até em suas sensações, pelo valor econômico dos objetos. E como "não resta dúvida de que todo o nosso conhecimento começa pela experiência", pois “[...], na ordem do tempo, nenhum conhecimento precede em nós à experiência e é com esta que todo conhecimento tem o seu início" e, ainda, "que outra coisa poderia despertar e pôr em ação a nossa capacidade de conhecer senão os objetos que afetam os sentidos e que [...] põem em movimento a nossa faculdade intelectual [...]" (Kant, 1994, p. 36). Nada existe no intelecto sem que antes tenha passado pelos sentidos. Portanto, é a capacidade intelectual das pessoas que está sendo moldada por todo esse processo modernizador, industrial, capitalista, produtor de mercadorias. Há uma verdadeira "adulteração na vida sensorial" (Pucci; Ramos de Oliveira; Zuin, 1997, p. 102).

A vida, modelada até as suas últimas ramificações pelo princípio de equivalência, esgota-se na reprodução de si mesma, na reiteração do sistema, e suas exigências descarregam-se sobre os indivíduos tão dura e despoticamente que cada um deles não pode se manter firme contra elas como condutor próprio de sua vida, nem incorporá-las como algo específico da condição humana. (Adorno, 1996, p. 400)

Então, se o capitalismo constitui um sistema econômico que em seu processo de produção e reprodução lança seus tentáculos e todo seu furor para além daquele campo, e com isso alcança as relações sociais construindo-as segundo o seu evangelho - ou seja, uma organização social produtora de um modus vivendi para os seres humanos que os obriga a agir de maneira exatamente idêntica ao que ele deseja -, é porque necessita disso para levar a cabo sua sobrevivência e reprodução.

Dessa forma, a cultura aqui não está sendo entendida apenas como uma dimensão do espírito completamente separado da produção material. Pelo contrário, é à lógica de produção material capitalista que a vida dos trabalhadores é forçada a se adaptar, mesmo que isso tenha levado décadas de violência contra eles. E também a serviço da expansão dessa lógica caíram todas as esferas da vida e do mundo que pudessem se tornar mercadorias. Então, a razão também se curvou e 
seguiu transformando a ciência em técnica para ampliar a produtividade capitalista. A matemática se tornou a principal ciência, pois tinha a capacidade de reduzir tudo a um mesmo denominador, a um quantum abstrato e calculável, igualando assim o que era diferente.

A razão instrumental burguesa, que serve de base para a industrialização, abarcou todas as formas de trabalho concreto anteriores a ela e as submeteu a um único modelo: o trabalho abstrato. Assim, nas sociedades ou em partes delas, nas quais o processo industrial capitalista modernizador ainda não estivesse totalmente instalado, o trabalho seria a atividade concretamente realizada pelo ferreiro, pelo carpinteiro, pelo pintor, pedreiro etc. Contudo, nas formações sociais já completamente abarcadas por aquela onda capitalista modernizadora, o trabalho aceitaria um caráter mais geral e distante do seu realizador, isto é, ele seria não mais uma atividade concreta, mas sim geral e abstrata. Marx (1989, p. 44) descreve o caráter abstrato adquirido pelo trabalho tomando por base a industrialização na sociedade capitalista burguesa associando-o ao seu produto:

Se prescindirmos do valor de uso da mercadoria, só lhe resta ainda uma propriedade, a de ser produto do trabalho. Mas, então, o produto do trabalho já terá passado por uma transmutação. Pondo de lado seu valor de uso, abstraímos, também, das formas e elementos materiais que fazem dele um valor de uso. Ele não é mais mesa, casa, fio, ou qualquer outra coisa útil. Sumiram todas as suas qualidades materiais. Também não é mais o produto do trabalho do marceneiro, do pedreiro, do fiandeiro ou de qualquer outra forma de trabalho produtivo. Ao desaparecer o caráter útil dos produtos do trabalho, também desaparece o caráter útil dos produtos nele corporificados, desvanecem-se, portanto, as diferentes formas de trabalho concreto, elas não mais se distinguem umas das outras, mas reduzem-se, todas, a uma única espécie de trabalho, o trabalho humano abstrato.

Antes, portanto, o trabalho tinha um caráter formativo: o ser humano, ao se afirmar no mundo, negando a natureza em seu estado bruto, transformando-a e com isso afirmando o espírito, transformava-se a si mesmo transformando o mundo. Mundo e ser humano nesse processo se aproximavam, se tocavam e se influenciavam mutuamente, pois nesse ato o ser humano subjetivava o objetivo e objetivava o subjetivo, compartilhando com o mundo sua construção - dele, ser humano construtor, e do próprio mundo - porque tinha total controle sobre o que estava fazendo, suas necessidades e seus objetivos. Dessa forma, o ser humano em seu relacionamento com o mundo, em sua experiência, objetivava-se construindo e dando nome ao que construía, erigindo uma cultura eminentemente humana, porque os objetos necessários para a sua sobrevivência possuíam a sua marca e uma única finalidade: a humana. Civilização material e cultura andavam juntas, unidas pelo trabalho num metabolismo humano/natureza.

Em contraposição a essa formação, a modernidade é caracterizada por um sistema econômico e social baseado na técnica, instrumentalizada como racionalidade 
a ser seguida com o objetivo específico de ganho e lucro empresarial - que em sua dinâmica atinge em cheio o ser humano vivente à época referida. A experiência desse ser, seus atos, atividades, comportamentos e pensamentos adquiridos com base em sua relação com o mundo e com os outros seres humanos são totalmente alterados, incidindo sobre o seu próprio mundo e de seus semelhantes. Até a relação consigo mesmo é mudada por essa nova formação econômica e social, não sendo mais possível um espaço totalmente íntimo, construído e verdadeiramente experimentado pelo ser humano, pois os fins já não são apenas e tão somente humanos.

Esse tipo de âmbito - a intimidade - foi retirado do homem e transformado em mercadoria. Não é mais o ser humano que sente por si mesmo, segundo uma cultura tradicional herdada de seus antepassados e baseada na religião, no mito ou em relações específicas com a natureza e com os outros seres humanos, mas sim um sistema lastreado numa racionalidade econômica, com fins totalmente externos aos seres humanos, quais sejam o ganho e o lucro, a impor-lhes pensamentos, sentimentos, comportamentos e maneiras de se relacionar com o mundo à sua volta.

Com essas observações, percebemos então que o processo educativo, isto é, formativo, na sociedade industrial não obedece mais a um processo baseado em atividades humanas concretas, com fins traçados, controlados e especificamente humanos, que até certo ponto individualiza os seres humanos em seu contato específico e rico com o mundo.

Tal composição - ou, podemos dizer, ambiente educativo - foi desfeita porque a produção industrial realizada em grande escala destruiu a possibilidade de especificidade e singularidade da formação, já que os objetos passaram a ser produzidos em série, compartilhando a mesma forma de produção e uso. Não é mais um determinado ser humano a realizar uma tarefa produtiva por meio de seus atributos herdados e desenvolvidos de forma particular e específica, mas sim uma massa amorfa de trabalhadores - realizando um trabalho abstrato, indiferente, geral, generalizado, indistinto e sobre o qual não tem o menor controle - e consumidores de produtos que só podem ser utilizados exatamente da mesma maneira por todos eles. Além disso, nessa formação econômica social, os produtos parecem ter surgido do nada, sem história, tamanha a alienação imposta aos produtores e consumidores diretos no sistema industrial produtor de mercadorias.

Nesse ponto já se iniciam as dificuldades para a educação formal apresentadas pelas escolas públicas, pois, como incitar um indivíduo a participar da construção de sua própria formação por meio de atividades de construção de textos, saberes, pensamentos, concatenações, leituras, entre outras, numa sociedade em que todos estão completamente alienados da produção dos objetos necessários à sua própria vida, não sendo necessário nenhum ato consciente dos indivíduos no intuito de produzir, consumir ou utilizar algo, já que tudo está completamente pronto para o consumo imediato? Se, com a educação formal, o educando pode se aproximar da gênese da vida - por meio de uma investigação dos princípios formadores do mundo, dos objetos, das ideias, dos outros e dele mesmo -, fora do âmbito desse tipo de educação o indivíduo é ensinado a não se interessar por tais assuntos, mas sim 
encontrar um caminho rápido até o pote de mercadorias (entendidas não apenas como objetos, mas também como serviços, imagens, textos etc.) que lhe trarão um fugaz gozo.

\section{O RITMO VELOZ DA MODERNIDADE E A PERDA DA POSSIBILIDADE DA EXPERIÊNCIA FORMATIVA: 0 AMBIENTE HOSTIL À EDUCAÇÃO FORMAL}

O exposto anteriormente acontece numa esfera social em que a experiência que o ser humano deveria ter, o construir por si mesmo - a experiência humana -, foi tomada dele e decidida por outrem, isto é, pela própria organização econômica e social. Sendo assim, tal organização acaba por se transformar numa segunda natureza para o ser humano, não permitindo mais que ele tome suas decisões com base em determinações religiosas ou ancestrais, portanto tradicionais, e muito menos individuais. Há nitidamente nessa nova configuração da vida do ser humano a modernidade, uma influência do modo de produção inerente às fábricas. Lá reina a produção massiva num curto espaço de tempo; todas as atitudes, gestos, atividades e pensamentos dos trabalhadores já estão preestabelecidos pela gestão técnica das operações e do tempo com vistas à sua maximização.

As fábricas são recintos em que a rapidez e o controle (taylorista) total dos indivíduos - transformados em massa de trabalhadores na esteira da produção fordista - ditam as regras da produtividade com o intuito de conseguir a máxima lucratividade. $\mathrm{O}$ modo de produção ora vigente impõe às empresas a necessidade de aferir o tempo de produção de forma milimétrica para que se possam tornar rentáveis e superar a concorrência, ou seja, sobreviver. Dessa forma, nenhum gesto, ato, pensamento ou comportamento pode estar fora do padrão já estabelecido pela gestão técnico-científica da fábrica, para não se correr o risco da perda de tempo, o que implicaria diretamente diminuição da produção.

Esse imperativo do uso do tempo na produção, sob a cadência veloz da racionalidade industrial capitalista, buscando a máxima produção no menor tempo possível, tem seu correspondente fora dela, ou seja, na troca - pois, se muitos bens são produzidos, eles necessariamente têm de ser consumidos em igual velocidade. Há assim uma aceleração em todos os âmbitos da vida moderna nas grandes cidades como consequência das relações de produção, de troca e das inovações técnicas. No momento em que se constrói uma racionalidade social na qual a velocidade acelerada é o lema, não resta para o ser humano outra forma de lidar com o que lhe é externo, e até interno, a não ser com rapidez e, em razão dessa, com superficialidade.

Esse modo de proceder acaba forçosamente internalizado pelos indivíduos, e o ritmo febril com que as indústrias se movimentam escorre para dentro da vida social, se infiltrando nas pessoas, naturalizando a extrema ligeireza com que tudo é feito em todas as esferas das experiências humanas. A rapidez, a brevidade e o reducionismo se tornam o lema da vida moderna e juntas a superficialidade e a efemeridade. Em decorrência disso, podemos chegar facilmente a uma conclusão: 
tudo que é experienciado de forma breve, rápida, superficial e reduzida não pode ser atingido em seu âmago, em sua essência, em seu todo e muito menos em seu processo de construção - que na verdade foi tomado do ser humano, relegando este último a apenas um apêndice da máquina.

Contudo, para se abreviar ainda mais a experiência possível do ser - que não pode perder tempo, pois tempo é dinheiro -, esta passa a ser decidida não por ele, mas, como já dito, pelo próprio sistema econômico/social e sua racionalidade técnica instrumental. As bases para essa economia de tempo, propiciada e imposta ao ser humano, são dadas pela ciência propulsora da técnica. Os instrumentos desenvolvidos na modernidade minimizam cada vez mais as atividades, tanto de trabalho quanto de outras áreas da vida, possibilitando assim uma rapidez jamais vista até então no desenrolar das tarefas diárias. O que antes levava horas ou dias para ser construído artesanalmente, agora pode ser materializado num "clique", sem esforço e sem uma experiência anterior para sua efetivação.

A experiência trazida de uma viagem pode ser abreviada por uma foto ou um filme desenvolvido em poucas horas; a experiência do preparo de um determinado alimento, que antes envolvia desde o plantio até o preparo propriamente dito, é reduzida a apenas a abertura de um recipiente. Essas novas experiências, oriundas do espaço urbano da modernidade, foram conceituadas por Walter Benjamin com base em alguns elementos comuns entre elas: a velocidade, a intensidade e a possibilidade de reduzirem uma série de processos a um gesto apenas, por isso ele as denominou de experiências do "choque":

Com a invenção do fósforo, em meados do século passado, surge uma série de inovações que têm uma coisa em comum: disparar uma série de processos complexos com um simples gesto. A evolução se produz em muitos setores; fica evidente entre outras coisas, no telefone, onde o movimento habitual da manivela do antigo aparelho cede lugar à retirada do fone do gancho. Entre os inúmeros gestos de comutar, inserir, acionar etc., especialmente o click do fotógrafo trouxe consigo muitas consequências. Uma pressão do dedo bastava para fixar um acontecimento por tempo ilimitado. $\mathrm{O}$ aparelho como que aplicava ao instante um choque póstumo. Paralelamente às experiências ópticas desta espécie, surgiam outras táteis, como as ocasionadas pela folha de anúncio dos jornais, e mesmo pela circulação na cidade grande. O mover-se através do tráfego implicava uma série de choques e colisões para cada indivíduo. Nos cruzamentos perigosos, inervações fazem-no estremecer em rápidas sequências, como descargas de uma bateria. Baudelaire fala do homem que mergulha na multidão como em um tanque de energia elétrica. (Benjamin, 1989, p.124-125)

As consequências para o ser humano dessas inovações técnicas e tecnológicas podem ter resultado em melhorias em sua vida material, todavia trazem consigo um empobrecimento de suas experiências formativas. Com o objetivo de otimizar a produção e controlar o operário, as atividades são reduzidas e facilitadas ao extremo, gerando a adição da descontinuidade nas operações fabris sintetizadas 
em movimentos mínimos que acabam por se tornar atos reflexos de autômatos. Obviamente, não há mais a necessidade de um desenvolvimento do conhecimento daqueles que realizarão a imensa maioria das atividades fabris ou de um aprofundado aprendizado para manusear as inúmeras inovações técnicas que surgem no campo produtivo fabril, já que a fundamental característica das máquinas que são construídas é a facilitação da sua operação, para que qualquer ser humano acostumado a utilizar apenas concatenações e raciocínios simples a realize e o lucro atinja níveis jamais vistos.

Mesmo nos escritórios ou repartições burocráticas, as tarefas não incluem análise, pensamento ou reflexão, mas apenas seguir procedimentos preestabelecidos. As grandes decisões, estratégias, elaborações técnicas e científicas ficam a cargo de uma ínfima minoria. Em decorrência disso, facilita-se também a própria vida do ser humano e reduz-se o tempo de suas atividades laborais ou cotidianas. Isso, associado às constantes e rápidas mudanças impostas pelo desenvolvimento tecnológico a serviço do sistema de produção capitalista, alimenta a não necessidade de uma grande habilidade, experiência e conhecimento em um determinado ramo de atividades, pois este se torna, num curto espaço de tempo, ultrapassado. É o saber geral, raso, fugaz e transitório que é exigido do ser humano, nada mais.

Esta lógica que orienta a forma de apresentação e a natureza mesma dos produtos tecnológicos é resultante da necessidade - certamente ditada por razões econômicas, mas não apenas por estas - de que estes possam ser manuseados mesmo por aqueles que não consigam executar esforços físicos ou não detenham determinado conjunto de conhecimentos, como as crianças, em um caso, os idosos, em outro. Do gesto de riscar o fósforo ao requerido pelo comutador que controla a iluminação doméstica, do clique do fotógrafo ao do usuário do micro-ondas ou do computador, é a mesma reação automatizada - a mesma experiência de choque que predomina. (Franco, 2004, p. 195)

O ser humano adquire, convivendo num contexto como esse, uma natural predileção pelo que é breve, rápido e sintético, não suportando o que demanda um tempo maior de dedicação, concentração e cuidado. As mudanças que vão acontecendo no cenário econômico e social da urbanidade ocidental, em suas primeiras décadas, deixam impossível a comunicação entre gerações, já que o relato de uma não pertence mais à realidade da outra em razão da velocidade das alterações que acontecem em todos os aspectos da vida (a própria velocidade não faz parte do contexto anterior de vida do ser humano). A atividade de relatar, ou seja, narrar as experiências pelas quais um ser humano passa - noutras palavras, contar histórias -, praticamente deixa de existir. Isso não vai mais sendo praticado em razão do novo modo de produção que age em outro ritmo, um ritmo acelerado, artificial e abstrato, completamente diferente da produção artesanal, em que a cadência era lenta, as relações eram orgânicas e geravam a possibilidade de experiências, tanto desenvolvidas, vividas, quanto transmitidas. 
A experiência transmitida pelo relato deve ser comum ao narrador e ao ouvinte. Pressupõe, portanto, uma comunidade de vida e de discurso que o rápido desenvolvimento do capitalismo, da técnica, sobretudo destruiu. A distância entre os grupos humanos, particularmente entre gerações, transformou-se hoje em abismo, porque as condições de vida mudam em ritmo demasiado rápido para a capacidade humana de assimilação. [...] Esse caráter de comunidade entre vida e palavra apoia-se ele próprio na organização pré-capitalista do trabalho, em especial na atividade artesanal. $\mathrm{O}$ artesanato permite, devido a seus ritmos lentos e orgânicos, em oposição à rapidez do processo de trabalho industrial, e devido a seu caráter totalizante, em oposição ao caráter fragmentário do trabalho em cadeia, por exemplo, uma sedimentação progressiva das diversas experiências e uma palavra unificadora. (Gagnebin, 1994, p. 10-11)

\section{A SOCIEDADE ARTESANAL, O TEMPO BREVE E A FORMAÇÃO ADQUIRIDA: O AMBIENTE PROPÍCIO À EDUCAÇÃO FORMAL}

Walter Benjamin separa, segundo Leandro Konder (1989, p. 146) e Jeanne Marie Gagnebin (1994, p. 15), dois âmbitos da atividade humana: um da pura e simples vivência e outro da experiência. Assim, há a grande experiência coletiva, de longa duração, construída e adquirida por meio do conhecimento lentamente acumulado e transmitido por gerações, a Erfahrung; e há a Erlebnis que é a vivência individual, isolada, rápida, constituída de impressões rápidas e fortes, assimiladas tão rapidamente quanto são deixadas para trás.

É possível dizer que a Erlebnis é a vivência do instante ou, como diria Benjamin, a vivência dos choques. Mais uma vez vem à tona o poder de percepção dos pensadores que foram englobados sob a alcunha de Escola de Frankfurt, pois, nas primeiras décadas do século passado, Benjamin já detectava a morte da narrativa. Numa incipiente sociedade moderna, esse estudioso já havia percebido a tendência de não haver mais nem narradores nem espectadores para a sua narração. Em seu texto "O narrador: considerações sobre a obra de Nikolai Leskov" (1994a, p. 197-221), Benjamin assevera a baixa na atividade de narrar em razão da própria experiência humana estar também naquela posição e, segundo ele, em vias de desaparecer totalmente - algo que estamos presenciando. Diz o teórico:

É como se estivéssemos privados de uma faculdade que nos parecia segura e inalienável: a faculdade de intercambiar experiências. Uma das causas desse fenômeno é óbvia: as ações da experiência estão em baixa, e tudo indica que continuarão caindo até que seu valor desapareça de todo. Basta olharmos um jornal para percebermos que seu nível está mais baixo que nunca, e que da noite para o dia não somente a imagem do mundo exterior, mas também a do mundo ético, sofreram transformações que antes não julgaríamos possíveis. (idem, p. 198) 
Para chegar a essas conclusões, o autor investiga e percebe não apenas a superfície do clima cultural e das atitudes dos seres humanos mergulhados na modernidade. As análises de Benjamin se aprofundam até chegar às fontes da cultura que propiciam a baixa no ato de narrar. Nelas ele percebe uma mudança nas estruturas que fornecem margem às experiências dos seres humanos, a saber, as estruturas produtivas capitalistas modernas que avançam sobre o antigo modo de produção ainda baseado no trabalho artesanal.

A narrativa, que durante tanto tempo floresceu num meio artesão - no campo, no mar e na cidade -, é ela própria, num certo sentido, uma forma artesanal de comunicação. [...] Assim se imprime na narrativa a marca do narrador, como a mão do oleiro na argila do vaso. [...] seus vestígios estão presentes de muitas maneiras nas coisas narradas, seja na qualidade de quem as viveu, seja na qualidade de quem as relata. Não admira que ele [Leskov] tenha se sentido ligado ao trabalho manual e estranho à técnica industrial. (idem, p. 206, grifos nossos)

É evidente nas palavras de Benjamin a perda da possibilidade de autonomia e autenticidade humana, isto é, experiência, no ambiente construído pela sociedade industrial que padroniza tudo numa única forma (mercadoria) de produção, consumo e relacionamento social. O sistema industrial produtor de mercadorias iguala todos os objetos e pessoas com o objetivo de trocá-los, isto é, relacioná-los, retirando deles, pessoas e objetos, suas qualidades pessoais (o que dificultaria a troca, pois os transformaria em únicos). Temos, então, uma forma social em que a experiência dos indivíduos já é experienciada pelo próprio modo de produção anteriormente a eles. Para compreendermos a crítica de Benjamin em relação ao contexto que produziu a perda da possibilidade da experiência, devemos nos remeter novamente à explicação da sua ideia de experiência, isto é, a Erfahrung. Para isso, serão utilizadas agora as explanações da professora Olgária Matos (2009, grifos nossos). Diz ela:

Etimologicamente, para experiência, a palavra que Walter Benjamin usa é Erfahrung. O seu radical é "fahr" que significa viajar. No antigo alemão, "fahr" é atravessar uma região, durante uma viagem, por lugares desconhecidos. E a palavra latina para experiência tem como radical "per" (experiência): sair de um perímetro, sair da condição do já conhecido, do já vivido, para ampliar vivências, acontecimentos e repercussões desses acontecimentos novos nas nossas vidas. E, de "per", também vem a palavra periculum: atravessar uma região, durante uma viagem, onde perigos podem nos assaltar. E, para esses perigos, há a palavra que se associa a periculum, que é oportunus - originada de portus, que quer dizer saída. Então, as experiências que nos acontecem durante uma travessia no desconhecido, numa viagem, são experiências que alargam nossa identidade, nosso conhecimento, nossa sensibilidade, nossa condição no mundo. Ora, no presente, com a contração do tempo, a experiência foi abolida. A experiência era algo que se transmitia de geração em geração, no sentido de que: narrativas comunicáveis se faziam como modelos exemplares de ensinamentos para gerações vindouras. 
Ora, a experiência então só pode ser admitida como tal quando acrescenta algo ao ser humano para que ele possa se relacionar e entender melhor o mundo em que vive. Isso significa fundamentalmente adquirir novos conhecimentos e com eles alterar o comportamento, isto é, a relação com o mundo. Noutras palavras, efetivamente formar-se, ou seja, educar-se. O novo, portanto, o diferente, o desconhecido, são elementos essenciais para que haja a experiência, pois, ao serem compreendidos e assimilados de forma crítica, conferem uma autenticidade a quem os assimila.

Essa autenticidade é conseguida por meio da autonomia do homem de, durante a "viagem", apreender e relacionar as informações novas com as que já possui, erigindo daí sua própria formação, com isso alimentando sua própria autonomia. É uma dinâmica que vai sendo produzida em camadas ao mesmo tempo em que as produz. Porém, a experiência é um processo que só pode acontecer num movimento lento de contato, análise e assimilação crítica; nunca num movimento irrefletido de imediata aceitação do que é apresentado e acomodação. A viagem, construtora da experiência, se dá ampliando as qualidades do viajante, num tempo lento de degustação, apreciação, saboreando as experiências; a rigor, experienciando-as.

Mas na vida atual o presente eterno é o princípio motor dos dias de cada um - aliás, de cada ser humano ora vivente. Pois o padrão de atitudes e comportamentos, a redução da capacidade de pensamento, reflexão e imaginação, o estímulo exacerbado das funções psicomotoras e outras imposições objetivas da atual formação econômica e social transformam a repetição em uma única forma de vida e, sendo assim, impossibilitam a experiência, já que essa é pautada não pela repetição cega de atos, atitudes e pensamentos (ou não pensamentos), e sim pela adição de conhecimentos.

E essa adição só pode acontecer aproveitando-se o tempo, isto é, adentrandose criticamente em novas situações, ambientes, práticas, relações, sorvendo-as em aprendizados, contemplações, impressões e outras sensações que acrescentam importantes elementos em nós mesmos. Tal qual Fedro, de Platão (2005, p. 55-125) guardadas as devidas proporções de imposições sociais objetas -, que no diálogo com Sócrates, ao encontrar um bom lugar para discutir com seu amigo o discurso de Lísias sobre o amor, tem, por intermédio de seu interlocutor, a possibilidade de refletir profundamente sobre aquele sentimento. Porém, como podemos observar em relatos de alunos, isso não é o encontrado entre eles. $\mathrm{O}$ videogame, a televisão, o computador (para alguns mais abastados) e o celular são as fontes de seu contato com o mundo, tomando o dia de todos eles.

Ora, se esses aparelhos apresentam uma tecnologia que possui sempre um mesmo padrão de operacionalização - imposto em sua forma pela mediação econômica-, de práticas e (não) raciocínios diante deles, além dos mesmos conteúdos, sobre os quais (conteúdo e operacionalização) os indivíduos não têm o menor controle ou influência, o que temos é um dos momentos da impossibilidade da experiência, objetivada pela relação de produção e consumo em que muitas pessoas estão inseridas. 
Isso demonstra uma atitude - inconsciente - muito mais voltada a passar o tempo "matando-o", ou seja, repetindo sempre os mesmos atos, comportamentos, ausências, sensações e irreflexões, em vez de desfrutá-lo acrescentando novos pensamentos, atitudes, práticas, enfim, transformando o uso do tempo de quantitativo para qualitativo, ou seja, alcançando as experiências. É fácil depreender daqui mais um motivo para os alunos não se interessarem pela educação formal, já que essa sempre apresenta novos conteúdos que demandam processos cognitivos intensos e mudanças constantes na forma de construí-los, numa maturação que exige um tempo lento de elaboração e reelaboração.

Dessa separação entre experiência e vivência, fica clara, como foi dito antes, a distinção entre os contextos que as originaram: a Erfahrung, advinda de uma formação econômica e social na qual predomina o trabalho artesanal; e a Erlebnis, oriunda da relação de trabalho e do contexto industrial. Na primeira, o tempo para produção acontece num ritmo lento, burilado, verdadeiramente formativo, isto é, no contato com a natureza o ser humano vai se construindo com sua obra, passo a passo, estágio a estágio, negando a matéria bruta e afirmando seu espírito; afirmando a realidade material num novo patamar (subjetivado) e negando o espírito em um isolamento transcendente.

No contexto da Erfahrung, o ser humano realiza sua obra do começo ao fim, sendo obrigado a elaborar estratégias para ultrapassar dificuldades de sua consecução, raciocínios complexos para concebê-la e desenvolver habilidades manuais para construí-la. O produto por ele concebido é realizado por inteiro, sem descontinuidades no processo de sua elaboração. Assim, ele ao mesmo tempo constrói e é construído em seu metabolismo com a natureza; ao mesmo tempo em que dá forma a algo bruto, forma-se enquanto ser humano.

Para Benjamin, essa forma de experiência guarda semelhanças com o trabalho artesanal [...]. Em ambos, o tempo segue o ritmo da mão, da respiração, e não distingue o passado como algo encerrado, fechado a novas interpretações. Como o trabalho manual e coletivo do artesão no ateliê, para o qual cada ato é uma camada que "agrega valor" ou que carrega em si o valor do todo, também a experiência pode ser entendida como uma sedimentação lenta de várias experiências que, mesmo distantes temporalmente, são atuais, na medida em que se fazem presentes a todo instante. (Palhares, 2008, p. 78)

Nessa belíssima definição do trabalho artesanal, podemos encontrar escondida a maneira que se edifica o conhecimento: uma lentidão de sobreposições de camadas que não dispensam as anteriores, pelo contrário, necessitam delas para sua composição, tensionando-as e chegando a um novo patamar, uma nova camada impensável sem a anterior. Uma continuidade indestrutível, construída num processo que leva em consideração o passado, mas que está aberta para questioná-lo. Temos então uma assimilação do tempo num outro ritmo, numa outra duração: a longa duração, pois, para interagir com o mundo com o propósito de entendê-lo, não há outra maneira. É somente com o mergulho nas profundezas dos objetos do 
mundo (e no próprio mundo) que podemos conhecê-los; e para isso necessitamos de tempo, ritmo lento e paciência - requisitos necessários também à educação formal.

Isso é com o intuito de burilar e refinar o nosso próprio conhecimento, assimilando-o, porém o questionando, formulando questões a nós mesmos no processo e assim nos desenvolver enquanto ser humano em formação. Caso contrário, ao traçarmos a rota mais curta e rápida para a chegada, inapelavelmente navegaremos na superficialidade e, nessa profundidade, correrendo o sério risco de, sem perceber os recifes e os bancos de areia, naufragar.

Contudo, esse tempo lento, fundamental para as verdadeiras experiências, não faz parte da realidade econômica, social e cultural engendrada pela produção industrial capitalista de mercadorias. Nela o tempo lento foi banido, e todos fogem da lentidão e da demora como o diabo da cruz. "Tempo é dinheiro", diz o ditado do apressado ser humano da sociedade industrial produtora de mercadorias.

Diante disso, Benjamin assevera: "As rugas, as marcas em nossas faces, são as assinaturas das grandes paixões que nos estavam destinadas, porém nós, os senhores, não estávamos em casa" (Benjamin apud Matos, 2009). E "não estávamos em casa" porque já estávamos atrasados para algum compromisso; então apressadamente saímos, velozes pelas ruas, tentando acompanhar o movimento acelerado da sociedade contemporânea. Porém, é no tempo lento, calmo e extenso que as experiências são possíveis. Desse modo, temos, com a constituição da sociedade moderna, estabelecido um ambiente hostil à experiência, nos termos de Benjamin.

O tempo no capitalismo se torna, então, totalmente vazio, pois é um terreno árido para as experiências em virtude da velocidade em que a vida dos seres deve ser vivida. A aceleração da produção industrial ultrapassa os muros fabris e invade a vida cotidiana dos modernos. Assim, todos os atos, atividades, produções, relacionamentos no mundo moderno sofrem uma contração e passam a existir numa velocidade que os esvazia de sentido e possibilidade de aprendizado, isto é, da experiência. Surge daí uma única forma para as atividades humanas: a encurtada, rápida, lépida e em mudança constante.

Num mundo em que só há essa possibilidade de práxis, o ser humano acaba por se habituar e perder a capacidade de interagir - noutras palavras, viver - consigo, com os outros e com o mundo de outra forma que não seja curta e veloz. $\mathrm{O}$ moderníssimo indivíduo, premido pelo clima econômico, social e cultural, passa a viver nos atalhos e despreza a possibilidade de experenciar atividades demoradas e completas. $\mathrm{O}$ ser humano assimila essa forma e vai à busca, movido pelo contexto, de aprimorá-la, ou seja, aumentar ainda mais a sua velocidade. Com isso, não aceita mais objetos, ações, interações, atividades que, como já dito, não sejam curtas e velozes, e passa a viver no andamento do cronômetro, não suportando qualquer segundo de demora ou inatividade.

Basta uma simples verificação da linguagem utilizada nos $e$-mails ou nas "salas de bate-papo" e constataremos que tanto jovens em idade escolar quanto adultos utilizam abreviaturas nas palavras para se comunicar - muitas vezes ininteligíveis para os não iniciados nessa prática regressiva. Para comprovar essa afirmativa, podemos 
prestar atenção em nós mesmos. Um simples rememorar de nossas próprias atitudes confirmará essa análise: quantas vezes ficamos absolutamente impacientes em frente à tela de poderosos - entendam velozes - computadores enquanto eles demoram alguns segundos para executar um comando que nós rapidamente impusemos?

Essa aceleração leva à, no limite, total inação, pois desejamos que as atividades sejam realizadas numa velocidade tal que seria melhor encontrá-las já prontas, e aí passarmos a outras que, por sua vez, seguindo a mesma lógica, estariam também concretizadas. Trata-se de "uma renúncia a si mesmo" que traz "prazer de substituição pela identificação com o poder” e chega ao cúmulo da situação exemplificada por Adorno na frase: "a música escuta pelo ouvinte"(Adorno, 1999, p. 102). Essa situação, objetivamente não permite nenhuma intromissão genuína, autônoma e autêntica do indivíduo sobre o mundo, em razão da mediação econômica que se totalizou.

As mercadorias são produzidas numa velocidade cada vez maior e numa padronização nunca antes vista. Para chegar a esse ponto, a tecnologia erigiu condições de controle e precisão incomensuráveis, tanto sobre aquele que produz quanto sobre quem consome alguma mercadoria.

Vivemos um momento em que os objetos, os relatos dos indivíduos, as formas de agir, de se comportar, de usar, de (não) pensar, parecem tão iguais quanto alucinatórias. Essa situação (possível de ser constatada numa mera observação dos adolescentes em sala de aula ou pessoas num metrô) parece demonstrar que todo o vestígio verdadeiro humano - como a mão do oleiro - foi retirado daquilo que superficialmente identificamos como humano. Afirmamos isso simplesmente porque humanos não são idênticos, são diferenciados por suas qualidades, comportamentos, decisões etc. - pelo menos deveriam ser -, e para produzir esses traços é necessário um mínimo de autonomia.

O que temos então é um "mercado absurdo dos homens sem qualidades" (Jappe, 1997, p. 7). E, "No clima da semiformação, os conteúdos objetivos, coisificados e com caráter de mercadoria da formação cultural, perduram à custa de seu conteúdo de verdade e de suas relações vivas com o sujeito vivo...” (Adorno, 1996, p. 396). Em outras palavras, o contexto propício às experiências humanas é totalmente inexistente. Nesse âmbito, perde-se tanto a possibilidade de narrativa quanto o interesse por ela, pois experiências ímpares ou verdadeiramente humanas (únicas, originais, autênticas, autônomas, fora do mercado dos choques, ou, nos termos de Adorno, vivas) não possuem mais espaço na sociedade industrial, tornando-se quase impossíveis, estranhas e desinteressantes:

O “homem de espirito", expressão hoje tão desacreditada, é um caráter social em extinção. O pretenso realismo que o sucede, no entanto, não está mais próximo das coisas, mas simplesmente disposto, à custa de quaisquer toil and trouble, a ocupar uma existência espiritual e a apoderar-se do que esta lhe traga. Assim desaparecem os jovens ou compositores que sonhem em ser grandes poetas ou compositores; [...] A formação cultural requeria proteção diante das atrações do mundo exterior, certas ponderações com o sujeito singular, e até lacunas de 
socialização. "Entendo a linguagem do éter, jamais a linguagem dos homens", escrevia Hoelderlin; cento e cinquenta anos depois, um jovem que assim pensasse seria objeto de chacotas ou seria entregue, sob a alegação de autismo, a um benévolo tratamento psiquiátrico. (idem, p. 399)

Para os alunos, ter uma experiência formativa pela educação formal é absolutamente desinteressante, porque o caminho é árduo, já que não possui mercadorias, agitação regressiva e choques audiovisuais. Além disso, a aceleração e o encurtamento das atividades no mundo fora da escola impedem qualquer interesse por parte do aluno por práticas necessárias à educação formal, isto é, que requeiram uma maior atenção, aprofundamento, e por isso um debruçar demorado, pensativo, crítico e reflexivo - muitas vezes ininterrupto - para burilar o produto final de tais práticas.

Elas são também absolutamente desnecessárias, pois Adorno (1999, p. 102), referindo-se ao que ele chamou de "masoquismo da audição" para criticar o comportamento das massas em relação à música estandardizada, demonstra haver uma tendência social que leva ao comportamento adaptativo dos indivíduos modernos. Essa se daria numa relação de troca que resulta na substituição de si mesmos pelo prazer da identificação com o poder.

Como "poder", nosso entendimento nos leva a crer em todo o processo de identificação pelo qual é exposto o ser humano moderno por meio da indústria cultural, resultando numa conformação do seu comportamento e (não) pensamento em algo denominado "massa" (consumidores, ouvintes, trabalhadores, cidadãos etc.). Noutras palavras, identificar-se com o poder, fazer parte dele, é se entregar aos ditames do sistema produtor de mercadorias, difundidos pela indústria cultural, até não poder ser distinguido mais de nenhum outro elemento produtor ou consumidor e deixar-se guiar pelas proposições daquela indústria sem nenhum pensamento ou questionamento original. Dessa forma, o desaparecimento da narrativa por falta de público - principalmente entre aqueles que mais deveriam ser habituados a ela: os alunos - é um exemplo triste da massificação que obstrui a cultura letrada e impossibilita a educação formal.

No atual contexto da vivência, isto é, da contemporaneidade, existe por parte da maioria dos alunos das escolas públicas e privadas um entendimento e uma busca de liberdade, consubstanciados na indisciplina e na desordem; porém, eles expõem o cego, rígido e fiel acompanhamento dos ordenamentos econômicos e sociais aqui tratados anteriormente. Trata-se da materialização do pseudoindivíduo adorniano: aquele que acredita ser absolutamente livre em seus atos e escolhas, mas não percebe a invasão de sua privacidade pela mediação econômica.

Concentração e controle, em nossa cultura, escondem-se em sua própria manifestação. Não camuflados, eles provocariam resistências. Por isso, precisa ser mantida a ilusão e, em certa medida, até a realidade de uma realização individual. A manutenção disso está fundada na própria realidade material, pois enquanto o controle administrativo sobre processos vitais é concentrado, a propriedade permanece difusa. [...] Por pseudoindividuação entendemos o 
envolvimento da produção cultural de massa com a auréola da livre-escolha ou do mercado aberto, na base da própria estandardização. (Adorno, 1986, p. 123)

Nas atividades aparentemente mais infantis, pacíficas e ingênuas, já se esconde a perfídia da relação econômica, conspurcando a interação social. A brincadeira que colore os céus das periferias paulistas foi tacitamente abarcada pela forma mercadoria e engendrou pequenas empresas produtoras em série das conhecidas e seculares pipas. $\mathrm{Na}$ atualidade, existem várias lojas especializadas na fabricação e venda de pipas; não há mais a artesanal produção desse brinquedo, e com isso se perdeu mais um momento propício a várias experiências. A relação social tornou-se uma só: mercadológica. E, na reprodução do ingênuo brinquedo, passou a vigorar a mais pura competição: primeiro de venda, e depois entre aqueles que noutros tempos apenas brincavam, mas hoje disputam a posição de serem destruidores da brincadeira alheia - ação que acontece numa verdadeira batalha aérea entre as pipas empinadas por seus donos (com o fio da pipa embebido numa substância que o transforma em verdadeira navalha), que do chão manipulam o fio guia com o intuito de cortar o fio das pipas alheias que, levadas pelo vento, estão no céu.

E, como as pipas valem dinheiro, há também uma enorme corrida atrás daquelas que têm seu fio cortado e jazem de volta ao chão. $O$ objeto material pipa, ao ser engolido pela forma mercadoria, passa a carregar intrinsecamente a ideologia da sociedade industrial produtora de mercadorias. As pipas passam a carregar consigo o poder de investir um alto grau de status àquele que a possui, desde o primeiro a comprá-la até aquele que consegue tomá-la quando, numa acirrada disputa, o dono original perde o seu controle.

Assim, fica evidenciada a totalização da forma mercadoria sobre os objetos e espaços mais recônditos da sociedade atual. Essa forma não tem como escopo a educação formal do sujeito, mas sim sua própria reprodução. Para isso, erige um ambiente ávido por ganho e lucro, negligenciando qualquer outro aspecto objetivo ou subjetivo. Um exemplo absolutamente claro disso é a indústria cultural e seus produtos: esses últimos interessam àquela indústria apenas enquanto produzem o lucro desejado, após esse período são descartados.

Para ela, indústria cultural, não importa o exemplo que cada um dos seus produtos fornece à massa de seres humanos, desde que estejam vendendo. Não importa se os ídolos que ela produz, e influenciam multidões, mal tenham passado pela escola e mesmo assim faturem quantias exorbitantes. Para a indústria capitalista, não importa se vendem livros, flores ou bombas, mas que estejam sempre vendendo. Não importa se, com sua lógica, estão construindo um ambiente que acelera a vida de todos à velocidade da luz, reduzindo as atividades a nada e impedindo qualquer tipo de experiência, desde que todos comprem mais.

Por trás de toda a hipócrita propaganda, veiculada por governos e entidades particulares, sobre a relevância da "educação" para a melhoria da sociedade, esconde-se um profundo desdém em relação à educação formal e a todos que nela estão 
envolvidos. Caso contrário, as preocupações estariam voltadas para a produção de um contexto verdadeiramente voltado à formação, isto é, à cultura letrada por meio da educação formal.

\section{CONCLUSÃO}

$\mathrm{Na}$ contemporaneidade, a forma que encapsulou toda a materialidade - isto é, a razão em seu estágio mais avançado, a saber, a forma mercadoria - não permite que o ser humano viva a verdadeira experiência, pois ela evoca a possibilidade de ser daquele que a exerce. A forma mercadoria obstaculiza a possibilidade já existente do ser humano existir enquanto sujeito e objeto, reconhecendo-se em sua plenitude e não identidade entre ambos (sujeito e objeto), o que lhe impeliria a revoltar-se contra a opressão da forma única, a razão transformada em práxis racional ou trabalho. Assim, a mesma forma que a impossibilita faz dela uma possibilidade histórica, porém real, já que o estágio das forças produtivas atuais nos permite a libertação da violência do sacrifício da labuta diária.

Não obstante, a experiência diz respeito também a um crescente e novo cabedal de conhecimentos. Na formação econômica e social aludida por nosso texto, o novo, o verdadeiro, o real são obnubilados pela forma valor, núcleo da produção econômica, que não permite a existência a tudo que não seja ela mesma, isto é, que não possa gerar mais-valia e, no limite, lucro. Ora, como não pensar na influência cabal de tal forma na educação dita formal? Se experiência é formação e formação é o homem no mundo, a constituição desse mundo é ao mesmo tempo influência e influenciada pela forma constitutiva produzida pelo homem, mas tornada autônoma do mundo.

A produção do mundo é a produção dos homens. Não apenas na escola, pois essa é também produzida nesse processo; ela é parte, nunca pode ser tratada como todo. O todo é ditatoriamente a forma econômica que sacrifica a tudo e a todos. Nesse sacrifício cai a experiência. Toda e qualquer alusão à educação formal deve ser permeada pelo raciocínio que leva em consideração, como imperativo da atual formação do ser humano, a troca. Qualquer investigação, ensaio, livro, digressão, enfim, qualquer reflexão sobre a educação formal e a cultura letrada nos tempos atuais que se faça sem levar em consideração tal fato é absolutamente falsa, pois analisa a parte como todo. Como desdobramento disso, Adorno (1996, p. 389) nos ensina:

Reformas pedagógicas isoladas, indispensáveis, não trazem contribuições substanciais. Poderiam até, em certas ocasiões, reforçar a crise, porque abrandam as necessárias exigências a serem feitas aos que devem ser educados e porque revelam uma inocente despreocupação frente ao poder que a realidade extrapedagógica exerce sobre eles.

O todo é o mundo, suas determinações, a "realidade extrapedagógica" que determina a realidade pedagógica. Como a razão se impôs e dominou o todo, é a forma valor, a forma mercadoria, noutras palavras, a formação econômica e 
social que encerra o restante da vida neste mundo. Todo aquele que escreve sobre educação nunca deveria se esquecer disso em vez de insistentemente considerar o conhecimento, o aluno, a escola ou a educação formal como um elemento isolado, analisando-o separadamente do restante do mundo.

O ser humano faz parte deste mundo, portanto ele é parte. Assim como a escola também é. Mas com isso não há nenhuma intenção de ressuscitar aqui discussões anacrônicas sobre teorias da reprodutibilidade. O ponto é o da forte influência da produção do mundo externo à escola na formação dos seres humanos que nela convivem. A rigor, tal mundo não permite a realização da experiência, pois condiciona substancialmente a percepção, a sensibilidade e o interesse dos seres humanos numa direção, ritmo, velocidade e capacidade perceptivas diametralmente opostas àquelas necessárias ao indivíduo para desenvolver uma relação com a cultura letrada. Essa última não consta, não é requisito prioritário em absolutamente nenhum dos afazeres diários dos humanos contemporâneos. Aqui poderíamos novamente citar Adorno (1996, p. 403) e dizer: "Quem compreende o que é poesia dificilmente encontrará um posto bem pago como autor de textos publicitários”.

A verdadeira formação se realiza negativamente graças ao estrondoso desenvolvimento econômico. Este é um momento em que as forças produtivas têm a capacidade de libertar os humanos do infortúnio triunfal. No entanto, as relações de produção, a consciência e toda a natureza interior reprimidas e estacionadas num estágio anterior e sempre regressivo não permitem tal libertação. Daí a incapacidade da experiência formativa se realizar como síntese (Aufhebung).

\section{REFERÊNCIAS}

Adorno, Theodor W. Sobre música popular. In: CoHn, Gabriel (Org.). Theodor Adorno: sociologia. São Paulo: Ática, 1986. p. 123. (Grandes cientistas sociais).

Teoria da semicultura. Educação E̋ Sociedade, Campinas: Papirus; CEDES, ano XVII, n. 56, p. 388-411, dez. 1996.

O fetichismo na música e a regressão da audição. In: ADORNo. São Paulo: Nova Cultural, 1999.p. 65-108. (Os pensadores).

Benjamin, Walter. Sobre alguns temas em Baudelaire. In: Benjamin, Walter. Charles Baudelaire: um lírico no auge do capitalismo. Tradução de José Carlos Marin Barbosa e Hemerson Alves Baptista. São Paulo: Brasiliense, 1989.p. 103-149. (Obras escolhidas, v. 3).

. O narrador: considerações sobre a obra de Nikolai Leskov. In: Benjamin, Walter. Magia e técnica, arte e política: ensaios sobre literatura e história da cultura. São Paulo: Brasiliense, 1994a. p. 197-221.

. Experiência e pobreza. In: Benjamin, Walter. Magia e técnica, arte e politica: ensaios sobre literatura e história da cultura. Tradução de Sérgio Paulo Rouanet. São Paulo: Brasiliense, 1994b. (Obras escolhidas, v. 1). p. 114-119. 
Franco, Renato. Tecnologia e cultura na época da globalização. In: Zuin, Antônio Alvaro Soares; Pucci, Bruno; Ramos de Oliveira, Newton (Orgs.). Ensaios frankfurtianos. São Paulo: Cortez, 2004. p. 191-206.

Gagnebin, Jeanne Marie. Prefácio: Walter Benjamin ou a história aberta. In: Benjamin, Walter. Magia e técnica, arte e política: ensaios sobre literatura e história da cultura. São Paulo: Brasiliense, 1994, p. 7-19.

JAPPE, Anselm. O mercado absurdo dos homens sem qualidades. In: Kurz, Robert. Os últimos combates. Rio de Janeiro: Vozes, 1997. p. 7-12.

Kant, Immanuel. Introdução. In: Kant, Immanuel. Crítica da razão pura. Lisboa: Fundação Calouste Gulbenkian, 1994. p. 36-60.

Konder, Leandro. Notas de tradução. In: Walter Benjamin. Charles Baudelaire: um lírico no auge do capitalismo. São Paulo: Brasiliense, 1989. (Obras escolhidas, v. 3).

Marx, Karl. Mercadoria e dinheiro. In: Marx, Karl. O capital. Rio de Janeiro: Bertrand Brasil, 1989.v. 1, p. 41-161.

Matos, Olgária. Tempo sem experiência. CPFLCultural, 6 jun. 2009. Disponível em: $<$ http://www.cpflcultura.com.br/integra-tempo-sem-experiencia-olgaria-matos $>$. Acesso em: 16 jul. de 2009.

Palhares, Tânia. Benjamin: experiência e vivência. Arqueologia da modernidade e perda da aura. Revista Mente, Cérebro \& Filosofia: fundamentos para a compreensão contemporânea da psique, São Paulo: Duetto editorial, n. 7, p. 76-82, 2008.

Platão. Fedro. São Paulo: Martin Claret, 2005.

Pucci, Bruno; Ramos de Oliveira, Newton; Zuin, Antonio Alvaro Soares (Orgs.). A educação danificada: contribuições à teoria crítica da educação. Rio de Janeiro: Vozes; São Paulo: Universidade Federal de São Carlos, 1997.

\section{SOBRE O AUTOR}

Cesar Augusto Alves da Silva é doutorando em psicologia escolar e do desenvolvimento humano pela Universidade de São Paulo (USP). E-mail: cesaraa@usp.br 


\section{CESAR AUGUSTO ALVES DA SILVA}

\section{Experiência moderna e as dificuldades para a educação formal}

$\mathrm{O}$ presente texto possui como objetivo refletir sobre o estreitamento e a padronização da formação dos seres humanos pelo âmbito conceituado de "experiência". Valendo-se dessas reflexões, verifica a influência da nova constituição desse âmbito sobre 
a percepção e aceitação de indivíduos da educação formal de ensino fundamental e médio. Tal reflexão se deve às ideias desenvolvidas por Walter Benjamin sobre essa possibilidade humana. $\mathrm{O}$ autor percebe que a redução do espaço para o desenvolvimento autônomo de atos e atividades que constituem a experiência começa a acontecer no momento do aparecimento e expansão do modo de produção capitalista. Além disso, Benjamin afirma que essa nova forma de produção da vida provocava a destruição de caminhos inteiros da tradição que os seres humanos trilhavam para desenvolver suas capacidades, sensibilidades e percepções que hoje seriam fundamentais para a relação de ensino e aprendizagem.

Palavras-chave: experiência; modo de produção; capitalismo.

\section{Modern experience and the challenges to formal education}

This paper aims to reflect on the narrowing and standardization of the formation of buman beings through the framework conceptualized as "experience". Drawing on these reflections, it examines the influence of the new constitution of this context on the perception and acceptance of formal primary and secondary education by individuals. This reflection stems from the ideas developed by Walter Benjamin about this human possibility. He realized that reducing the space for autonomous development of acts and activities that constitute the experience occurred at the time of the emergence and expansion of the capitalist mode of production. In addition, Benjamin argues that this new form of production of life destroyed entire paths of the tradition that humans trod to develop their skills, sensitivities and perceptions that today would be fundamental to the teaching and learning relationship.

Keywords: experience; mode of production; capitalism.

\section{Experiencia moderna y las dificultades para la enseñanza convencional}

Este texto tiene el objetivo de reflexionar sobre el estrechamiento y la estandarización de la formación de los seres humanos a través del marco conceptualizado como "experiencia". A partir de esas reflexiones comprueba la influencia de la nueva constitución de ese ámbito en la percepción y aceptación por parte de individuos de la educación formal de la escuela primaria y secundaria. Dicha reflexión se debe a las ideas desarrolladas por Walter Benjamin acerca de esa posibilidad humana. El autor se da cuenta de que la reducción del espacio para el desarrollo autónomo de los actos y actividades que constituyen el experimento ocurrió en el momento de surgimiento y expansión del modo de producción capitalista. Además, benjamin afirma que esa nueva forma de producción de la vida destroza porciones enteras de toda la tradición de que los seres humanos transcurrían para desarrollar sus habilidades, sensibilidades y percepciones que hoy serian fundamentales para la relación entre enseñanza y aprendizaje.

Palabras clave: experimento; método de producción; capitalismo. 